\title{
Households' Willingness to Pay for Community Based Health Insurance Scheme: in Kewiot and EfratanaGedem Districts of Amhara Region, Ethiopia
}

\author{
Eshetu Mamo (MSc) (Corresponding author) \\ Ethiopia Health Insurance Agency, PO BOX 164, Debre Berhan, Ethiopia \\ Tel: 251-912-215-732Ｅ-mail:eshetumamo2006@gmail.com
}

Getamesay Bekele (PhD)

Department of Economics, Debre Berhan University

PO BOX 3011CODE 1250, Debre Berhan, Ethiopia

Tel: 251-912-049-636Ｅ-mail:getamesaybkk@gmail.com

Received: July 8, 2017 Accepted: August 15, 2017

doi:10.5296/ber.v7i2.11513ＵRL: https://doi.org/10.5296/ber.v7i2.11513

\begin{abstract}
The purpose of this study is to examine determinants of Rural Households' Willingness to pay (WTP) for Community Based Health Insurance Scheme, in Kewiot and EfratanaGedem districts of Amhara region, Ethiopia. A cross-sectional design that followed a quantitative approach was used. Pre-tested structural and interviewer administered questionnaire was used to collect the desired data. A total of 392 sample rural households were taken by systematic random method. The contingent valuation method of double bounded dichotomous choice format (with calibration strategy) is applied to elicit households' willingness to pay for the scheme. An interval regression model is used to estimate the mean willingness to pay and to explore the degree of association between predicted WTP and predictor variables. Households' WTP for the scheme is found significantly associated with factor variables such as gender, education status, family size, level of awareness about the scheme, respondents' trust in the scheme management, family ill health experience, households' perceptions on health service quality, and their annual income level. The mean WTP amount is found 211ETB (\$10.5) per annum per household. The result clearly shows that $79 \%$ rural households are willing to pay for the scheme. Therefore, despite these factors affecting the rural households' WTP, there is a potential demand for the community based health insurance scheme. We suggest that, among
\end{abstract}


others, to improve the quality of health care and to build up community awareness and trust on the scheme management have paramount to enhance households' WTP and hence, to expand health insurance coverage.

Keywords: Community Based Health Insurance, Willingness to Pay, Double Bounded, Calibration Strategy, Ethiopia

\section{Introduction}

Achieving universal and equitable access to quality health care requires a sustainable financial resource that meets the health needs of the population, without causing impoverishment. Such accesses can contribute to the attainment of development goals and economic growth through improved health status (Ahuja, 2004). However, around 1.3 billion people globally lack access to the most basic health care, while 100 million people are pushed into poverty because of direct payments for health care services (Ejughemre, 2014). The situation is more serious in developing countries and while governments still strive to tackle poverty, the issue of health care financing for the poor has remained unsolved, which causes vicious circle of poverty (WHO, 2005 and Weil, 2013). In addressing this issue, health financing systems through general taxation and with the development of health insurance are generally recognized as two important strategies to achieve universal health coverage (Carrin et al., 2005).In tax-funded systems, the population contributes indirectly via taxes, where as in health insurance systems (e.g. social health insurance and community based health insurance) individuals, households and organizations directly pay the premium on the basis of employee's salary or means of income (Wiesmann, 2000).

Community based health insurance (CBHI), sometimes called community pre-payment schemes, is widely accepted as viable option to increase both vertical and horizontal equity in health, specially in the rural area of developing countries (Ejughemre, 2014). The reasons behind for encouraging CBHI schemes are its particular role to reduce financial barriers to health care utilization and its redistributive effects (Binam et al., 2007). Among others, South Korean, Ghana and Rwanda are best example to take lessons from developing countries, while South Korea is often cited as a success story for its rapid achievement of universal health coverage through national health insurance (Xu et al., 2010). However, in most African countries, public and private health insurance covers almost exclusively the formal sector and, therefore, achieves no more than 10 percent of the population coverage. As a result, having majority of their population involving informal sector, number of African countries have been implementing CBHI scheme (Noubiap et al., 2013 and Ejughemre, 2014).

In 2010, Ethiopia also introduced health insurance program with the mission to achieve universal primary health coverage, i.e providing basic package of essential health service for all Ethiopian. However, social health insurance is still on its preparation to start, while CBHI scheme is at its pilot stage, and hence, national health insurance implementation is remaining behind its goal (Anagaw et al., 2015). Based on health insurance guideline of the Federal Ministry of health $(\mathrm{FMoH})$, Amhara National Regional State (ANRS) had designed the regional community based health insurance scheme which was begun in 2011 only in three pilot districts, and till 2015 it had been expanding to 98 districts. Among these, Kewiot and 
EfrataGedm are the two pilot districts in north showa zone of the region, where CBHI scheme was established in 2013.Eventhough the local governments have been striving to promote the general benefit of the CBHI scheme, health insurance coverage is too low(only31\% in 2015), while high dropout rate was recorded in subsequent two years. Thus, it shows that the CBHI scheme is less likely to sustain unless major improvements to be done which requires an investigation on household's willingness to pay for the scheme.

On the other hand, CBHI scheme is based on voluntarism (not obligatory), so that households are assumed free to choose between pay and/or not to pay for the scheme premium. Moreover, in principle it requires high community participation in all round including premium setting (Defourny et al., 2008). However, households' WTP in these districts was not assessed at all. Thus, it was very important to examine rural households' willingness to pay (WTP) for the scheme in the study area, which required employing contingent valuation method (Cameron, 1988; Hoyos \& Mariel, 2010 and Ejughemre, 2014).

In this regard, different empirical studies were conducted based on contingent valuation method(CVM) to value households'(individual's) willingness to pay for community health insurance schemes(Binam et al.,2007;Ataguba,2008;Onwujekwe et al.,2009; Oriakhi et al.,2012;Bukola \& Usman,2013 and Tundui \& Macha,2014). However, they used a single bounded dichotomous choice (SBDC) and or another bidding game approach which are considered statistically less efficient to elicit information about households' actual WTP (Champ et al., 2009). This study used double bounded format which is recently recognized as statistically efficient to elicit stated preference of WTP. More specifically, the methodological contribution of this study is the application of calibration method to control the hypothetical bias inherent in the CVM method so that ex-post certainty calibration of 'yes' responses yields a more efficient estimation (Loomis, 2013).

Therefore, this study assessed the voluntary and community based health insurance scheme, aiming to investigate rural households' WTP and to contribute for health insurance policy environment. Specifically, the study had the following objectives.

- To describe households' willingness to pay distribution (using both double bounded and single bonded response) for CBHI scheme

- To investigate factors affecting households' willingness to pay for the CBHI scheme (using double bounded dichotomous choice).

- To estimate the average amount of money that households' are willing to pay for CBHI Scheme.

\section{Literature Review}

A significant number of studies have been used CVM to estimate the WTP for CBHI scheme in some rural areas of developing countries. So far, the review made on such literatures focused on biding format, findings of WTP amount and its determinant factors are discussed below.

Dong et al., (2004) examined households' differential WTP (from 688 households (HHs)) for 
CBHI premium for themselves and for other household members in North West Burkenafaso. It applied a bidding game elicitation format to collect WTP information. The report shows that the mean WTP for insurance for themselves (=3575 CFA) was twice more than their mean WTP as a whole (1759 CFA).Among other determinant variables, Age, Gender, income and educational level were found significantly associated with WTP. It showed that the old, the females, the poor and these with less schooling had a lower WTP than their counter parts (young, males, rich and these with more year of schooling respectively). This result is similar with the findings by Onwujekwe et al. (2009), conducted in Nigeria. The justification made by the later is that males stated higher WTP amounts than females could be an income effect because males generally earn more than females. It suggested that, those living in rural areas tend to be less willing to pay than those in urban areas because the former earn less and mostly depend on subsistence farming for survival.

Similarly, Binam et al.(2007) assessed households' WTP for CBHI scheme in Cameroon. The study was employed biding game format to elicit information from households $(n=837)$. It revealed that $67 \%$ of respondents were WTP for the CBHI scheme while the estimated average WTP was 9840FAFA (\$17) per year. Among others, household's income level, education, morbidity rate, Gender, community organization's experience, household's perception of the medical staff attitude and the availability of essential drugs at the health center were found significant variables determined WTP amount.

Ataguba (2008) also investigated households' WTP for the CBHI in Nigeria. It was based on unidirectional biding game type of elicitation format, which proposed the use of in-kind payment in the form of Agricultural commodities. The result shows that quarterly average WTP amount was estimated as N1010 (\$7.77). Variables such as Gender, households size, health status, quality of health care center, confidence in the proposed scheme, distance to the nearest health center and wealth, were significantly determine how much households WTP for the scheme. However, unlike many empirical studies (Binam et al., 2007, Adane et al., 2014 and Bukola \& Usman, 2013), it found that level of education has insignificant impact on WTP.

Oriakhi et al. (2012) conducted a study on determinants of rural households' willingness to participate in CBHI scheme in Nigeria (Edo State).The finding revealed that $56.4 \%$ ( out of 360 samples HHs) expressed their willingness to participate in the scheme. It also reported that household size and membership of the town association are key demographic factors, while income, medical expense incurred, credit opportunities were found important economic factors that significantly determine the rural households' willingness to participate.

Another cross sectional comparative study in Nigeria was conducted by Bukola \& Usman (2013) with the objective to assess the WTP for CBHI scheme among 450 rural and 450 urban households (HHs) in Osum State. Using open ended elicitation format, this study found that large number of rural households (82\%) were WTP than urban households $(51.6 \%)$, while the estimated average WTP amounts are N721.7K per year and N1798.9k per year, respectively. The study reported that size of household members, level of education, income, distance to the health center, marital status, age and male gender are major factors contribute 
to households' WTP for the scheme. The other important finding is that income variable is negatively and positively associated with rural and urban HHs WTP, respectively. Age variable also positively associated with the rural HHs WTP but negatively related with urban households' WTP.

Adane et al.(2014) assessed households' maximum WTP for the scheme in Fogera district found in North West of Ethiopia. The study employed double bounded format to assess maximum WTP. Using multiple linear regression models, it revealed that $80 \%$ of households were willing to pay for the scheme, while the mean amount of WTP was 187.4birr per year. The study revealed that gender, households' size, schooling experience, being farmer and merchant household, were significantly associated the WTP.

Tundui and Macha (2014) investigated the effect of social capital on HHs WTP for CBHI scheme in rural Tanzania. It used to unidirectional (single bonded dichotomous choice) biding game to elicit information about households' WTP ( $n=274 \mathrm{HHs})$. The result shows that social capital variables such as membership in social organization and network, Trust among community members, Trust on scheme management, and income level are positively and significantly related to WTP. On the other hand, unlike the pervious literatures, age of household heads, education level, household size, and participation in health insurance are found not affecting willingness to pay.

In general, these empirical studies were either based on open ended or closed ended biding game (including iterative biding game) that follows SBDC type of elicitation formats. In this regard, there is no absolutely correct and or universally accepted method to deal households willingness to pay (for any nonmarket good/services). However, many authors agreed on that the SBDC methods yields statistically less efficient to explain the actual WTP as compared to DBDC format (Champ et al., (2009)). These studies also couldn't address the hypothetical bias that most often leads to an over estimation of WTP. The results may, thus, not be fully reliable for policy purposes (Kedir, 2011 and Loomis, 2013).

\section{Methodology and Data}

\subsection{Data Source}

This study is based on a household survey using structured survey instruments (i.e interview questionnaires) to obtain desired data. Hence, it used solely primary data source.

\subsection{Sampling Strategy}

The study populations are all rural households who are currently living in these two pilot districts. In order to gather quantitative data, the list of totality of households in those two districts was considered as sample frame for the study, so that representative sample households were chosen. However, CBHI scheme is designed for whom only involved in informal sector.Hence, respondents who are working in the formal organization were excluded from the study. Beside, these two districts have similar socio-economic characteristics. Therefore, the sample size was calculated using single population proportion formula (Singh, 2007). In order to obtain these sample households, multi-stage sampling 
technique was employed as following. First stage, simple random sampling method was used to select sample "kebele" administrations. Therefore, taking the list of kebeles from each district as a sample frame, twelve Kebeles (six kebeles from each district) that accounts $32 \%$ of the total kebeles were randomly selected out of 38 total kebeles (18 in Kewiot and 20 in EfrataGedm).In the second stage, sample households were selected using systematic random sampling method.

\subsection{Method of Data Collection}

Quantitative data was collected from sample households through face-to-face interview. Structured questionnaire was prepared in English and for the purpose of easy communication during interview, the questionnaire was translated to local language 'Amharic', then back to English to ensure the consistency of language during data analysis. Before launching the final study, a pilot study was conducted. It had two objectives: (1) To test the design of the questionnaire (reliability and validity) and (2) To draw information of the relevant initial bid vector (described in section 3.4).

Therefore, content validity approach ${ }^{2}$ was employed to validate the research instrument, while reliability was tested using Cronbach's alpha, which is a common way of computing correlation values among the questions on instruments. The standardized test of alpha coefficient was found 0.9223 which shows the research instrument is reliable enough. The final face to face interview was took place from February 15, 2016 to May 25, 2016. A total of 422 questionnaires were administrated through face-to-face interview among sample households. Then, after discarding a few incomplete responses, a total of 392 questionnaires remain for the analysis. Thus, the response rate was $93 \%$.

\subsection{Elicitation Format and Bid Design}

Double bounded dichotomous choice (DBDC) model with follow up certainty question introduced by Champ et al. (1997) was used in this study, which requires setting a series of bid intervals so that respondents could be asked yes or no questions for both lower and upper bids. Here, the critical issue is how to set the initial bid amounts on which the second bids can be derived from. In this regard, some literatures suggest to use focused group discussion or to conduct pilot study (Hanemann et al., 1991 and Kedir, 2011). Thus, pilot survey was conducted among 50 households. After announcing the main objective of the pilot study, the maximum amount of money they are willing to pay per year and other basic socioeconomic information was collected using the first version of interview questionnaire. To fit the observed data points to underlying probability distribution, nonparametric kernel density estimation was used as shown by the figure 1 below.

\footnotetext{
${ }^{1}$ 'Kebele' is the lowest administrative body in Ethiopia which comprises at least population of 5000.

${ }^{2}$ Validity was traditionally subdivided into three categories: content, criterion-related and construct validity. Content validity includes any validity strategies focus on the content of the test (Brown, 2000).
} 


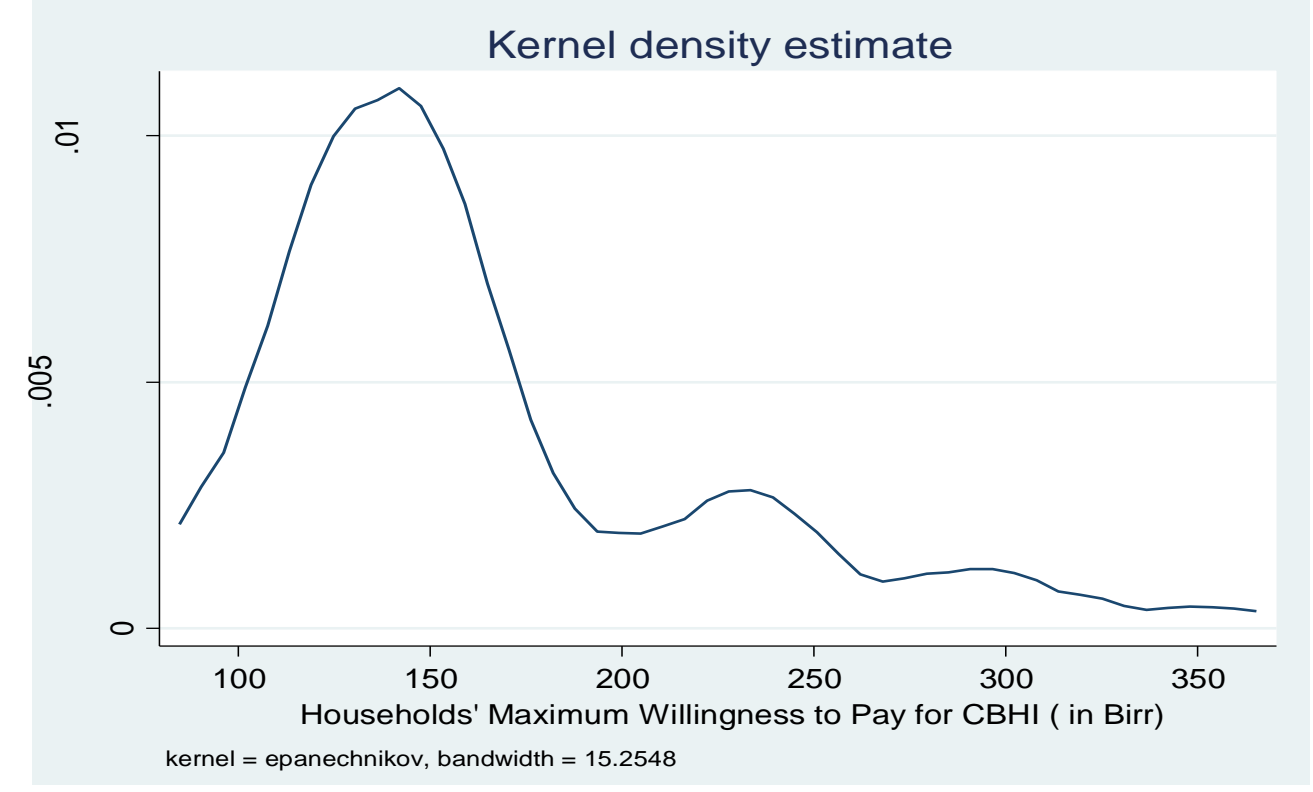

Figure 1. Kernel Density Estimates of Stated WTP from the Pilot Survey, 2016

The range of response of maximum WTP with open ended question varied from100 to 350 Ethiopian Birr (ETB), with high concentration in the range between 120 to 200ETB. For the observation greater than 200 and lower than 120, the bid values are associated with a low probability density value. On the other hand, the mean value of maximum WTP responses was found 164ETB, which is very close to 160 in the observation. Taking this observation as reference, two observation from above and two observations from below with equal interval, but in the range of higher kernel density ${ }^{3}$ probability, were taken as first bid amounts. Therefore, from observations around the mean, first bids were strategically set at ETB 120, 140, 160, 180 and 200, which were randomly allotted to sampled households in the final survey, as recommended by Champ et al. (2009).

More specifically, these starting bids were varied per 84 interview questionnaires. The second bid amounts were easily determined during the interview following the response of first bid. It was half of the first bid if the respondent said "no" and doubles if he/she said "yes" for the first bid. The figure below represented the general bid design framework.

\footnotetext{
${ }^{3}$ Kernel density is a estimators approximate the density $f(x)$ from observations on $x$ (maximum WTP values in this case).The data are divided in to none over lapping intervals, and counts are made of the number of data points within each interval. In more general kernel density estimates, the range is still divided into intervals, and estimates of the density at the center of intervals are produced (See Stata 11 Manual).
} 


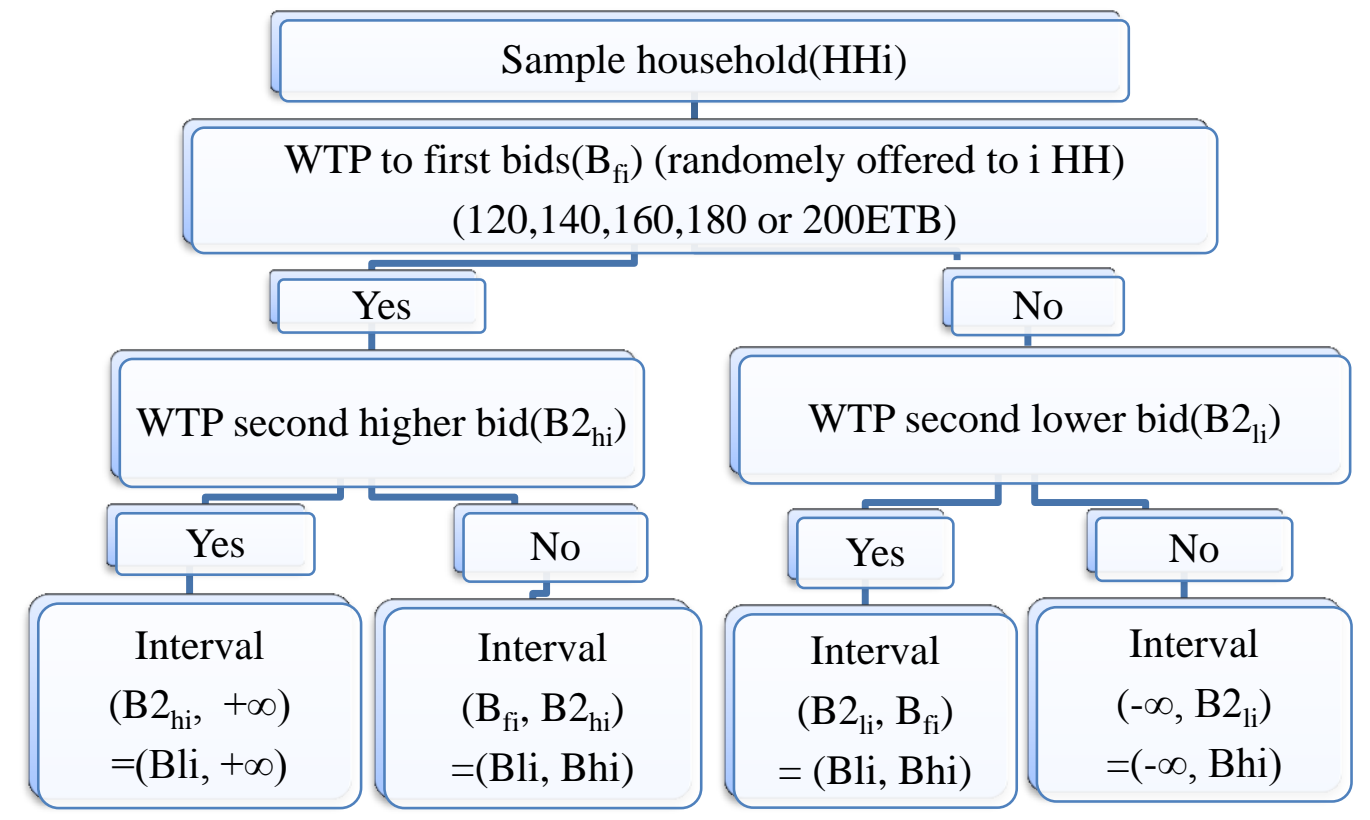

Figure 2.Bid Design and Households' Actual WTP Intervals

\subsection{Model Specification and Conceptual Framework}

To specify WTP model, it follows the econometric model used by Cameron (1988). The linear form of WTP function with two values (lower WTP and higher WTP) was used to predict the interval data model and the mean WTP. Let denote unobserved individual willingness to pay for the scheme as $W T P_{i}$, a vector of predictor variables (included based on the research question, theory and knowledge on the topic), which are demographic and socioeconomic data, social capital attributes and health and health insurance related information, as $x_{i}$ (see Table 1) and $\varepsilon_{i}$ as a residual component following a normal distribution with mean zero and standard deviation $\sigma$. Then, the WTP function to be estimated could be specified is:

$$
W T P i=X i^{\prime} \beta+\varepsilon i
$$

Where, $X i^{\prime}$ are predictor variables $\& \beta$ represents coefficients including constant term.

Using double bounded dichotomous choice format, two subsequent bids were offered to sample households. If individual sample household accepts (say yes) for the first bid (prescribed in the questionnaire), a higher bid would be offered to him/her in the second round question and vice versa. The outcomes of these two responses produce an interval for the actual WTP of a sample household. Thus, the actual WTP is unobserved by the researcher, rather distribute in three possible cases depending on the responses of the two bids offered.

Case1: "yes-yes" responses when WTP is above the second higher bid $\left(B 2_{h i}\right)$ and lies in the interval $(B l i,+\infty)$.

Case2: "no-no" responses when WTP is below the second lower bid $\left(B 2_{l i}\right)$ and hence lies in the interval $(-\infty, B h i)$. 


\section{Macrothink}

Business and Economic Research

ISSN 2162-4860

2017, Vol. 7, No. 2

Case3: "yes-no" when the WTP is between first bid $\left(B_{f i}\right)$ and second higher bid $\left(B 2_{h i}\right)$, or "no-yes" when the WTP is between the second lower bid $\left(B 2_{l i}\right)$ and first bid $\left(B_{f i}\right)$. Here, regardless the order of "yes-no" responses, the interval for WTP was set as (Bli, Bhi). Finally, the probability associated to each case, respectively, was set as following (Thomas, 2007).

$$
\begin{gathered}
\operatorname{Pr}(B l i<W T P i)=\operatorname{Pr}\left(\frac{B l i-X i^{\prime} \beta}{\sigma}<\mathrm{Zi}\right)=1-\Phi(\mathrm{Zli}) \\
\operatorname{Pr}(W T P i<B h i)=\operatorname{Pr}\left(\mathrm{Zi}<\frac{B h i-x i^{\prime} \beta}{\sigma}\right)=\Phi(\mathrm{Zhi}) \\
\operatorname{Pr}(B l i<W T P i<B h i)=\operatorname{Pr}\left(\frac{B l i-X i^{\prime} \beta}{\sigma}<\mathrm{Zi}<\frac{B h i-X i^{\prime} \beta}{\sigma}\right)=\Phi(\mathrm{Z} h i)-\Phi(\mathrm{Zli})
\end{gathered}
$$

Where, Bli denotes the lower bound, Bhi the higher bound of WTPi, $\mathrm{Z}$ is the standard normal variable and $\Phi($.$) is the cumulative distribution function of the standard normal$ distribution. The corresponding binary indicators can be denoted as:

$I i^{Y Y}=1$ if individual $i$ states "yes" twice, and zero otherwise

$I i^{N N}=1$ if individual $i$ states "no" twice), and zero otherwise

$I i^{Y N(N Y)}=1$ if individual $i$ states "yes" and "no" (regardless of the order), and zero otherwise.

Due to nature of outcome variable WTP set as intervals observation, maximum likelihood estimation method was employed (Williams, 2015). Therefore, the following log-likelihood function was derived to be maximized for $N$ independent observations, so that both $\beta$ and $\sigma$ have been estimated.

$$
\ln L=\sum_{i=1}^{N}\left[I i^{Y N(N Y)} \cdot \ln (\Phi(\mathrm{Zhi})-\Phi(\mathrm{Zli}))+I i^{N N} \cdot \ln (\Phi(\mathrm{Z} h i))+I i^{Y Y} \cdot \ln ((1-\Phi(\mathrm{Zli})](5)\right.
$$

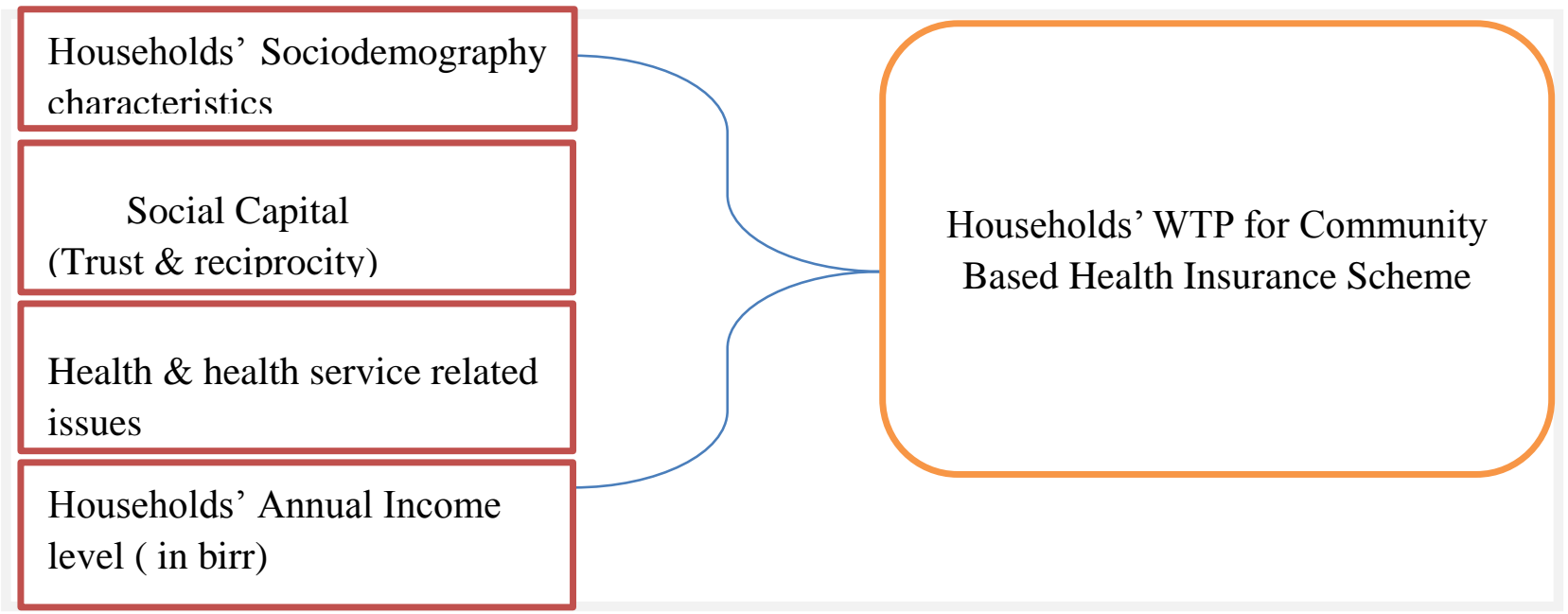

Figure 3. Conceptual Framework for WTP Model 


\subsection{Data Analysis}

During and after the field survey, the quantitative interview questionnaires were checked for missing responses and consistency of variables so that it was properly entered in SPSS version 16 program. Then data was exported to Stata 11 statistical program for analysis. Descriptive statistics was done to present the demographic and socio-economic characteristics of respondents in relation with the outcome variable (WTP). Interval data regression analysis at $95 \%$ confidence interval was done. Multicollinearity test ${ }^{4}$ was also conducted before estimation of the model, while robust option was used to minimize hetroscedasticity. The model goodness of fit $\left(\mathrm{R}^{2}\right)$ was found from "findit fitstat" online command. The unconditional mean WTP corresponds to the intercept, was estimated when all the explanatory variables have been removed from the model. It is the conservative way of estimating mean WTP by removing the explanatory variables from the WTP function (Conroy, 2005).

\section{Results and Discussion}

\subsection{Descriptive Statistics}

In this study, a total of 392 households were successfully interviewed and remain for the study analysis. The demographic data (in the Appendix-1) and the statistic result in table 1 shows that the majority of households $(74.7 \%)$ are male headed, and the rest are females. One hundred eight $(27.6 \%)$ and one hundred fifty two (38.8\%) respondents were, respectively, in the age group of 31-40 and 41-50, while the mean age of respondents was nearly 44 years. This was nearly similar with the study finding at 45 years average households' age reported by Adane et al. (2014) in the rural households of Fogera district of Gonder, Ethiopia. It is also found that two hundred one respondents (61.5\%) are Orthodox Christian, while 148(37.8\%) are Muslims followers.

The result also shows that the majority of respondents $87.2 \%(n=342)$ are married, which might not a surprising social aspect in almost all rural community of Ethiopia. It also revealed that $53 \%(n=209)$ household heads had educational background at primary level (1- 6 grade), $16 \%(n=61)$ had secondary level (above 6 grade), while nearly $31 \%(n=122)$ were illiterates (including informal education).One hundred eighty one (46.2\%) and 131(33.4\%) of rural households in the study area, are composed of family size grouped to 3-5 and 6-8, respectively. The mean amount of family size was found 5.7 which is slightly higher than the national statistics average family size of 5, surveyed in 2008. Regarding the occupation, majority of households (96\%) were farmers and only $4 \%$ involved in the petty trading as their main occupation. This indicates that in the study area the community source of income is almost all depends on farming activities.

\footnotetext{
${ }^{4}$ Multicolinearity is when two or more regressors are highly correlated with each other that can affect their influence on outcome variable. The value of VIF (variance inflation factor, the common way of testing multicollinearity) is found 2.41 , which is less than 10 , indicates there is no multicollinearity problem among regressors(Torre, 2007).
} 


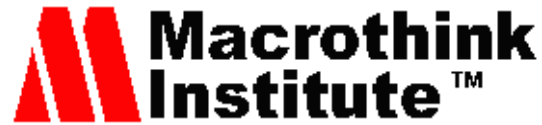

Business and Economic Research

ISSN 2162-4860

2017, Vol. 7, No. 2

Table 1. Descriptive Statistical Summary of Variables in the Study $(n=392)$

\begin{tabular}{|c|c|c|c|}
\hline Variable & Range & Mean (Proportion) & Standard Deviation \\
\hline Gender(gn) of Household Head & 0 to 1 & 0.747 & 0.435 \\
\hline Age(ag) & 22 to 69 & 43.883 & 9.559 \\
\hline Formal Education(educ) & 0 to 1 & 0.689 & 0.463 \\
\hline Family Size(fams) & 1 to 12 & 5.755 & 2.281 \\
\hline $\begin{array}{l}\text { Participation in Comm. } \\
\text { Association(pcass) }\end{array}$ & 0 to 1 & 0.725 & 0.447 \\
\hline Awareness about CBHI(awcbhi) & 0 to 1 & 0.663 & 0.475 \\
\hline Health Insurance Status (hhis) & 0 to 1 & 0.658 & 0.473 \\
\hline $\begin{array}{l}\text { Household's Trust } \\
\text { on Scheme(hhts) }\end{array}$ & 0 to 1 & 0.583 & 0.493 \\
\hline Family Health Experience(hhfhe) & 0 to 1 & 0.747 & 0.435 \\
\hline $\begin{array}{l}\text { Health Service Quality } \\
\text { Perception (hsqp) }\end{array}$ & 0 to 1 & 0.492 & 0.501 \\
\hline $\begin{array}{l}\text { Drug availability } \\
\text { Perception (drgavp) }\end{array}$ & 0 to 1 & 0.383 & 0.486 \\
\hline $\begin{array}{l}\text { Household's Annual } \\
\text { Income in birr(hhYi) }\end{array}$ & $\begin{array}{ll}6660 & \text { to } \\
74200 & \end{array}$ & 35331.61 & 13867.53 \\
\hline Bid1 & 120 to 200 & 160 & 28.50 \\
\hline $\operatorname{Bid} 2$ & 60 to 400 & 269.489 & 103.20 \\
\hline yesno1 & 0 to 1 & 0.788 & 0.409 \\
\hline yesno2 & 0 to 1 & 0.260 & 0.439 \\
\hline $\begin{array}{l}\text { Household's Maximum } \\
\text { WTP in birr }\end{array}$ & 0 to 330 & 213.444 & 72.12 \\
\hline
\end{tabular}

Source: Computed From field Survey, 2016

As shown in table 1 above, the study included social capital attributes, health and health insurance related information categorized as dummy variable. Regarding social capital, it was found that about $73 \%$ of respondents have been participating in community association (mainly 'eddirs') ${ }^{5}$, and only $58 \%$ of them have trust on the management of the community based health insurance program. About health insurance status, previously $66 \%$ of respondents have been involved in the health insurance membership and equal proportion also acquired enough awareness about the scheme. Majority respondents (75\%) assured that their family has been experienced ill health condition in last twelve months previous to interview. As it affects their WTP, households were also asked their perception towards health service quality (in terms of the whole medication to cure the ill health) and drug availability in the nearby health facility. While $49 \%$ perceived quality health service provision, only $38 \%$ of the respondents were perceived prescribed drugs are always available in the nearby health

\footnotetext{
5 eddirs- are funeral associations in Ethiopia that ensure a pay-out in cash and in kind at the time of a funeral for a deceased member of the family of a member of the group (Haile et al, 2013).
} 
facility.

Households' annual income was approximated from self-reported income of different sources. Regardless of large disparity of income (ranging from 6,660 to 74,200 birr), the households average annual income was found 35,332ETB. Majority of respondents (79\%) were accepting the first bid offered (range 120 to 200 ETB) and, hence, it can be considered as the percentage of households who are willing to pay for CBHI scheme. About $26 \%$ of respondents were accepting the second bid offered (range 60 to 400ETB), out of which17\% and $9 \%$ were accepting the second lower and second higher bids respectively. After the response for the two subsequent bids, households were asked to state their maximum WTP amount. With minimum zero and maximum 330, the average value of maximum WTP is found nearly 214ETB which is slightly higher than the estimated mean WTP from interval data.

The figure below presents the aggregate demand curves for CBHI scheme, derived from the yes responses for the first bids (panel a) and for the second higher bids (panel b). It indicates that the percentage of 'yes' responses based on the first bids and second higher bids are both downward sloping. However, panel (a) is flatter than panel (b), because relatively the higher the bid price interval (twice the first bid), relatively the lower demand for the insurance. The two curves implies that an inverse relation between the bid price and percentage of yes response. It goes with theory of a downward sloping Hicksian demand function (Autor, 2010), hence, health insurance scheme seams a type of "normal good".

Panel (a)

Panel (b)

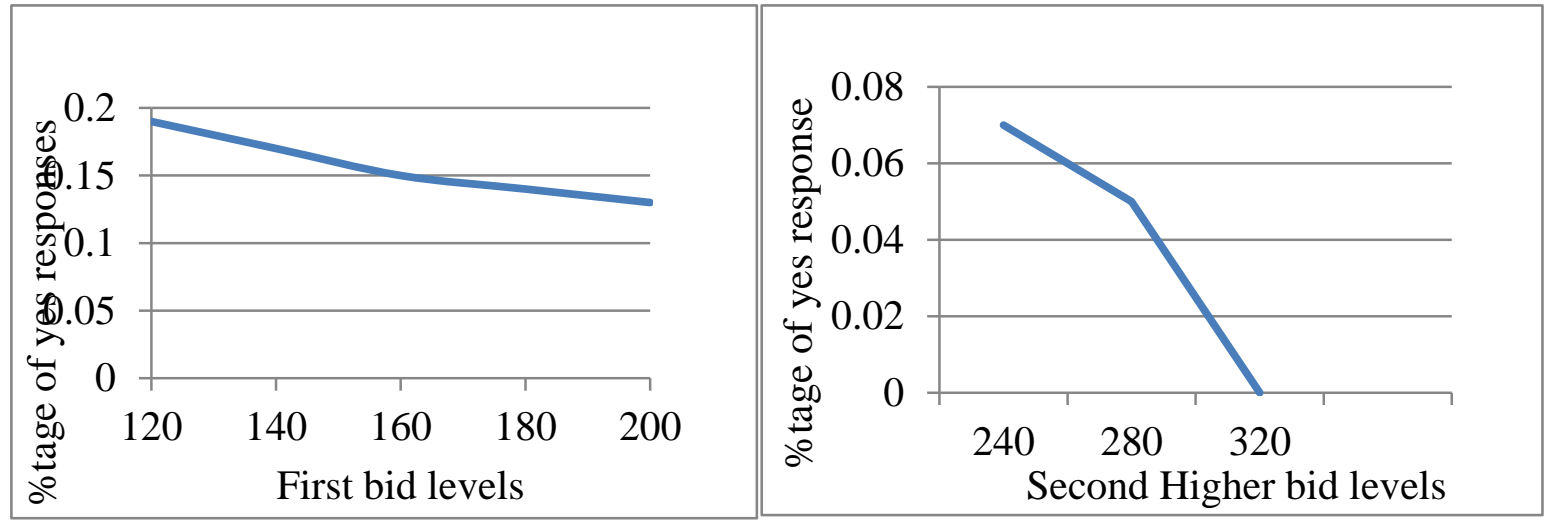

Figure 4. Aggregate demand curve for CBHI based on First bid and Second higher bid responses

Figure 5 below also presented the WTP distribution which is the value of responses for two bids as categories of interval data. The lower categories with negative infinity at lower limit are these with "no-no" responses, while the upper categories with positive infinity at higher limit are these with "yes-yes" responses. The remaining categories represent the 'yes no' responses regardless of the order. A close look of the percentage (above 10\% value) indicates majority of responses $(n=274)$ were lied in the categories of responses with lower limit ranges $(120,200)$ which is very similar with the result of the pilot survey and upper limit ranges $(240,400)$. Thus, it can be generalized that $70 \%$ households revealed their WTP 
ranging between 120 to $400 \mathrm{ETB}$. This is also the range which consists of the estimated mean WTP (211) (described under section 4.2.3).

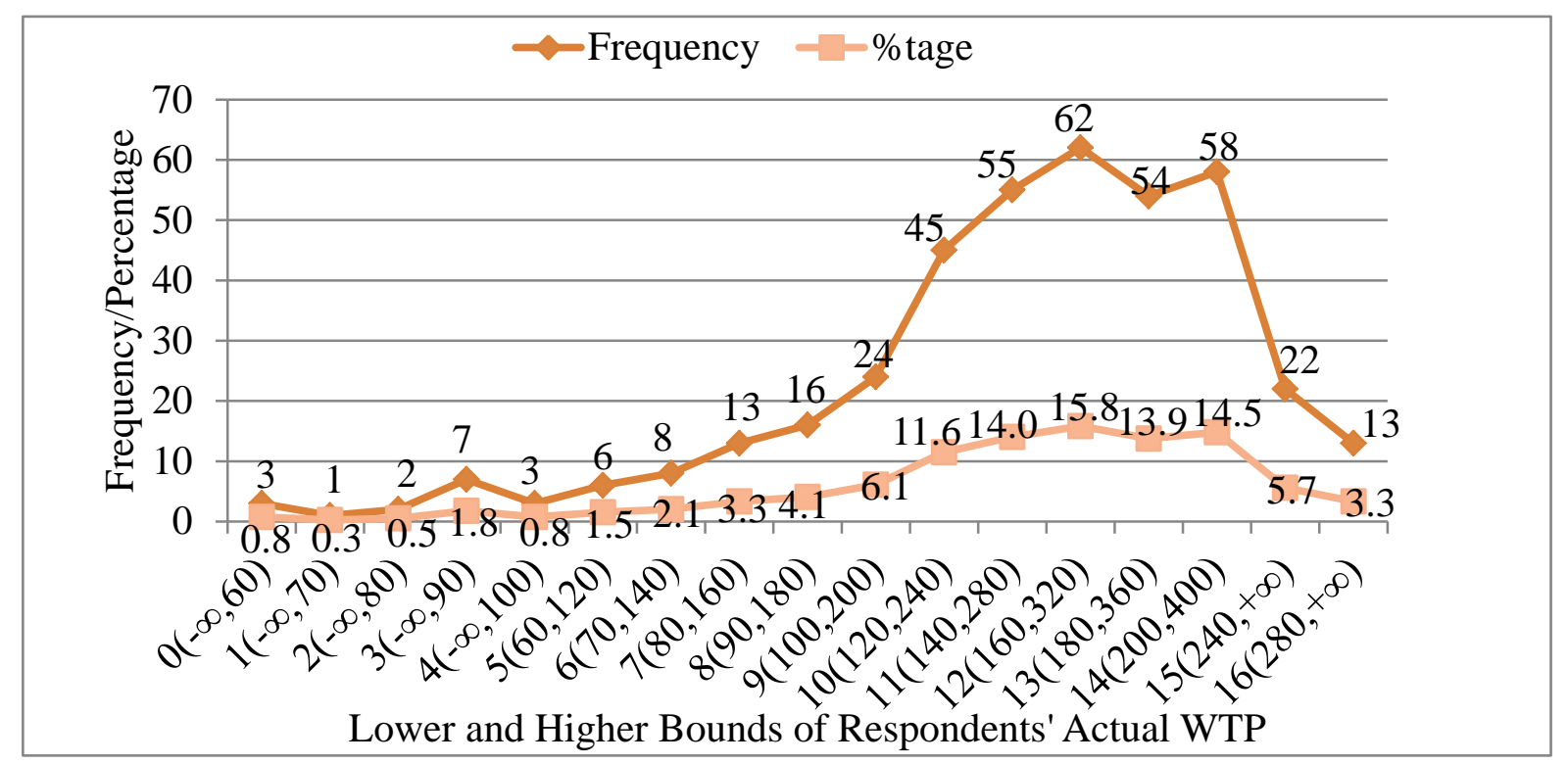

Figure 5.Respondents' WTP by Interval data Categories

\subsection{Econometric Model Analysis}

Interval regression with 'robust' option was conducted to minimize potential hetroscadesticity problem mostly inherent in cross sectional data, while direct hetroscadesticity-test was not appropriate in maximum likelihood estimation (Wooldridge, 2002). The two dependent variables of the study are defined by lower willingness to pay (lwtp) and higher willingness to pay (hwtp), for which the value of each observations was steamed from the responses (calibrated) for first and second bids offered. The regression result for the interval data of double bounded WTP model is shown in the table 2 below.

Table 2. Interval Regression (Estimation) Results

\begin{tabular}{|l|c|c|c|}
\hline Interval regression & \multicolumn{3}{c|}{$\begin{array}{l}\text { Number of observation=392 } \\
\text { Wald chi2(12)=1117.42 } \\
\text { Prob chi2=0.0000 }\end{array}$} \\
\hline & $\begin{array}{l}\text { Coeffeicint } \\
\text { (Robust Std.Err.) }\end{array}$ & Z- value & P-value \\
\hline Gender(gn) & $16.770(5.982)$ & 2.80 & $0.005^{* *}$ \\
\hline Age(ag) & $-0.284(0.498)$ & -0.57 & 0.569 \\
\hline Education(educ) & $14.614(5.392)$ & 2.71 & $0.007^{* *}$ \\
\hline Family Size(fams) & $8.695(2.113)$ & 4.11 & $0.00^{* * *}$ \\
\hline $\begin{array}{l}\text { Participation in Community } \\
\text { Association(pcass) }\end{array}$ & 3.554 & 0.66 & 0.508 \\
\hline $\begin{array}{l}\text { Awareness } \\
\text { CBHI(awcbhi) }\end{array}$ & $\begin{array}{c}(5.366) \\
(5.791)\end{array}$ & 4.55 & $0.000^{* * *}$ \\
\hline
\end{tabular}




\begin{tabular}{|c|c|c|c|}
\hline $\begin{array}{ll}\text { Households' } & \text { Insurance } \\
\text { Status(hhis) } & \\
\end{array}$ & $\begin{array}{l}10.983 \\
(5.382) \\
\end{array}$ & 2.04 & $0.041 *$ \\
\hline $\begin{array}{lll}\text { Households' } & \text { Trust } & \text { on } \\
\text { Scheme(hhts) } & & \\
\end{array}$ & $\begin{array}{l}10.088 \\
(4.493)\end{array}$ & 2.25 & $0.025^{*}$ \\
\hline $\begin{array}{l}\text { Households' Family Health } \\
\text { Experience(hhfhe) }\end{array}$ & $\begin{array}{l}24.168 \\
(6.099)\end{array}$ & 3.96 & $0.000 * * *$ \\
\hline $\begin{array}{l}\text { Health Service Quality } \\
\text { Perception(hsqp) }\end{array}$ & $\begin{array}{c}9.263 \\
(4.431)\end{array}$ & 2.09 & $0.037 *$ \\
\hline $\begin{array}{l}\text { Drug Availability } \\
\text { Perception(drgavp) }\end{array}$ & $\begin{array}{c}5.004 \\
(4.804) \\
\end{array}$ & 1.04 & 0.298 \\
\hline $\begin{array}{l}\text { Households' Annual } \\
\text { Income }\left(\mathrm{hhY}_{\mathrm{i}}\right)\end{array}$ & $\begin{array}{c}0.02 \\
(0.111)\end{array}$ & 5.53 & $0.000 * * *$ \\
\hline Constant Term & $42.727(14.521)$ & 2.94 & $0.003 * *$ \\
\hline Sigma & $19.525(1.740)$ & & \\
\hline $\begin{array}{r}\text { Observation Summary: } 16 \\
0\end{array}$ & $\begin{array}{l}\text { - Cencered obser } \\
\text { encered observati }\end{array}$ & $\begin{array}{c}35 \\
341\end{array}$ & $\begin{array}{l}\text { ed observ } \\
\text { cvation }\end{array}$ \\
\hline
\end{tabular}

$*, * *$ and $* * *$ denote statistical significance at $10 \%, 5 \%$ and $1 \%$ levels respectively.

\subsubsection{Interpretations}

The regression result shows that the log likelihood of the fitted model is -76.956783 , which is used in the LR-chi^ 2 test of whether all predictors' regression coefficients in the model are simultaneously zero (null hypothesis). Prob $>\mathrm{chi}^{\wedge} 2=0.0000$ is the probability of getting wald-chi2 statistic (or more), which would be compared with the specified alpha level (the willingness to accept a type I error) set at 0.05 .The Sigma $(=19.5)$ that the 'intreg' reports is equivalent to the standard error of the residual (Williams, 2015).In the observation summary, the left cencered observation $(n=16)$, right cencered observation $(n=35)$ and interval observation( $\mathrm{n}=341)$, respectively, represents the 'no,no', 'yes, yes' and 'yes, no plus no, yes' responses for the subsequent bids.

Thus, a p-value $=0.000(<0.05)$, tells us the WTP model as a whole is statistically significant (i.e at least one of the regression coefficients in the model is not equal to zero). To state differently, the LR-chi^ $2(\mathrm{df}=12)^{6}$ test indicates the null hypothesis of constant only model is rejected, and hence, the alternative hypothesis of the full model is accepted. The close look to the value of $\mathrm{P}>|\mathrm{z}|$, as compare with the significance level of 0.05 , shows that explanatory variables such as gender, level of education, family size, awareness of CBHI, previous health insurance status, trust for the scheme management, family ill health experience, perception to health service quality, and households' annual income level are statistically significant determinant of households' WTP for the scheme. Regarding the relationship of these socio economic variables with the outcome variable (WTP), all have expected sign. Rounding one digit, the regression equation can be set as:

${ }^{6} \mathrm{LR}\left(\mathrm{ch}^{\wedge} 2\right)=2(\mathrm{~L} 1-\mathrm{L} 0)$, where L1 \& L0 are the maximum likelihood of full and constant only models respectively (see Appendix-1). 
$W T P=42.7+16.8 g n-0.3 a g+14.6 e d u c+8.7$ fams $+3.6 p c a s s+26.4 a w c b h i+$ 11 hhis $+10.1 h h t s+24.2 h h f h e+9.3 h s q p+5 d r g a v p+0.02 h h Y i$

One important thing about interval regression, as opposed to other ordinal methods, is that the interpretation of the parameters can be done the same as the way for the OLS estimation does (William R., 2015). However, because the observed values for the outcome variable (WTP) are intervals, not exact values, the effect of these coefficients are on predicted value of WTP, not simply on the mean of observed values. Hence, interpretation of these coefficients is made accordingly (i.e based on ceteris paribus).

A nominal variable gender (gn) is statistically significant. While other variables held constant, as compared to female headed household, being male household head increases the predicted WTP for the scheme by 16.8ETB. This may be as a result of income effect, due to the fact that in most rural setting of Ethiopia, female's income is highly dependent on male and or earns money less than males. This finding is consistent with results obtained by Adane et al., 2014, Binam et al.,(2007), Dong et al.,(2004), Bukola \& Usman(2013) and Onwujekwe et al.,(2009).

The model also shows that the household head education status (educ) is significantly and positively affects the predicted amount of money they are WTP for the CBHI scheme. As compared to these who did not have formal education, these who attended formal education have 14.6 higher predicted WTP, holding other variables constant. This is in line with result of the studies done in Cameroon by Binam et al., (2007), in North West Burkinafaso by Dong et al., (2004) and in rural Nigeria by Ataguba et al.,(2007).

Households with larger family size are willing to pay a higher amount than households with smaller family size. Ceteris paribus, the coefficient of family size (fams) shows that one extra person join the household member increases the predicted WTP for the scheme by 8.7ETB. This may be due to the fact that rural households always link the probable financial burden they could face when their families seek medical treatment with the amount they are willing to pay for the scheme. This is inline with the study conducted in Fogera district, ANRS of Ethiopia, by Adane et al.(2014) and in Nigeria (Edo State) by Oriakhi et al.(2012).

The rural households in the study area, who are awared enough about the basic concept of CBHI program (awcbhi), tend to be more willing than their counterparts. Holding other variables constant, respondents' with enough awareness have 26.4ETB more WTP than these not awared households. This finding is consistent with the finding in rural Nigeria, reported by Ataguba et al. (2007).

The respondents' health insurance status (hhis) before interview is found positively influence their WTP for the scheme. Holding other variables constant, it shows that the insured households before interview have more WTP by 11ETB than these not insured. It was inconsistent with Adane et al.(2013), probably due to the difference in the experience of health insurance in terms of the time period since its establishment.

Households' trust (hhts) towards the general CBHI program management is found significantly and positively affects their WTP for the scheme. The coefficient indicates that, under constant 
condition in other predictors, respondents who have trust on the scheme management have more WTP by 10.1ETB than these who are distrusted. This finding is similar with the study finding in Nigeria conducted by Ataguba(2008) and in Tanzania by Tundui \& Macha(2014).

Household family ill health experience (hhfhe) is found another important factor that positively affects the amount of money they are willingness to pay for CBHI scheme. Holding other variables constant, respondents whose family was experienced ill health in last 12 months before interview revealed 24.2ETB higher predicted WTP than their counterparts. This result is consistent what was fond in Cameroon by Binam et al.(2007) and in rural Nigerian by Ataguba et al. (2007). Thus, perhaps, it implies that rural households traditionally linked their family ill health experience with the likely health cost in the future, and hence, consistent with theory of 'adverse selection behavior'.

The model also shows that health service quality perception (hsqp) is found another significant variable affecting the amount respondent are willing to pay for CBHI scheme. Respondents who perceived quality health service (provided by the near health facility), have 9.3ETB higher predicted willing to pay for the scheme than these who don't perceived quality health service, while holding other predictor variables in the model constant. This was found consistent with the study of Ataguba(2008) in Nigeria .

Households' annual income (hhYi) is also found an important variable in explaining their decision on the amount of willing to pay for the scheme. It shows that for one ETB increase in households' annual income, ceteris paribus, would increases the predicted WTP by 0.02ETB. This finding is consistent with number of study findings including the study conducted in rural Nigeria by Ataguba et al., (2007), in Cameroon by Binam et al., (2007), in Burkenafaso by Dong et al., (2014) and in Tanzania by Mach et al., (2014). Thus, the amount households are WTP for the scheme is an increasing function of their income level. This is due to the fact that they have been traditionally linked to the ability to pay principle.

\subsubsection{The Model Goodness of Fit}

A way to find $\mathrm{R}^{2}$ is the online "findit fitstat" stata command right after running the interval regression which provides a number of measures of fit. The Maximum Likelihood pseudo- $\mathrm{R}^{2}$ reflects a significant improvement of the full model over the intercept only model. Therefore, the WTP model having $72 \%$ explained variation is said to be reasonably fitted (see Appendix $-1)$.

\subsubsection{Estimation of Mean Willingness to Pay}

Interval regression without any predictor variables, actually the intercept is the only predictor, gives the estimated mean WTP i.e constant value (Conroy, 2005). Accordingly, the estimated result shows that the mean willingness to pay is found 211 ETB. This is less than the predicted mean value of 216 (i.e Marginal effects after intreg, linear prediction $=216.26696$ (see Appendix-1)).Therefore, as some literatures point out (Conroy, 2005 and Kedir, 2011) the conservative way of mean estimation is preferred for effective policy design. 


\section{Conclusion and Policy Implication}

The findings of this study revealed that majority (79\%) of the rural households in the study area were willing to pay for CBHI scheme. The average amount of money, they are willing to pay, was ETB 211(\$10.5) per household per annum. It is much higher than ETB 144, which is the annual premium value designed for pilot strategy, for which households up to five family members should pay. Therefore, it could significantly improve the source of health care finance and, hence, encouraging to launch the national health insurance program. However, the amount that households are willing to pay is found significantly associated with family head gender, educational status, level of awareness about the scheme, family size, level of trust households have on the scheme management, ill health experience in the family, and households' perception towards the quality of health care provision in the nearby health facility, and their annual income.

From the finding, the following are important points to be considered in the policy implication for the expansion of health insurance scheme. It needs health care quality indication to be developed in to the contracts between health insurance scheme and health service providers, so that health facilities could be monitored accordingly in terms of best practice in health quality assurance and standard treatment protocols. This monitoring and evaluation should be with incentives to promote quality care. It requires intensive awareness creation and trust building programs in the community, particularly for those don't have formal education and also for these don't insured before. The premium setting should take in to account the rural households family size and their income sources, while selective strategy to be include to support these female headed households not to be vulnerable groups in the community.

For future researches, it is better to employ principal component analysis method following wealth approach for estimation of income source of these rural households rather than household's self-estimated annual income used in this study. The study has also shows only the temporal relationship between dependent and independent variables. Thus, the researcher suggests comprehensive and long term prospective studies might provide better evidence in assessing households' willingness to pay or health insurance purchase.

\section{Acknowledgement}

Our great thanks and sincere appreciation goes to both Kewiot and EfratanaGedem district Administration staffs and CBHI officers for their firm cooperation during data collection. Special gratitude owed to two interviewers Ato Natan Hason and w/o Stehaynesh Debela, who fully involved with much devotion from the beginning to the end of data collection. This research also financed by Debre Berhan University and Ethiopia Health Insurance Agency. We thank all the administrative bodies in these organizations. We also thank Ato Habtamu Bekele for his kind support this publication.

\section{Reference}

Adane, K., Measho, G., \& Mezgebu, Y. (2014). Willingness to pay for community based health insurance among households in the rural community of Fogera District, North West 
Ethiopia; International Journal of Economics, Finance and Management Sciences, 2(4), 263-269.

Ahuja, R. (2004). Health insurance for the poor in India. Working paper no. 123. Retrieved from http://faculty.chicagobooth.edu/john.cochrane/research/papers/after_aca.pdf

Anagaw, M., Robert, S., Zelalem,Y., Getnet, A., \& Arjun, S. B. (2015). Dropping out of Ethiopia's Community Based Health Insurance scheme. Health Policy and Planning, 30, 1296-1306. https://doi.org/10.1093/heapol/czu142

Ataguba, J. T. (2008). Community Health Insurance Scheme as a viable option for rural population in Nigeria; Paper submitted to the Centre for the Study of African Economies (CSAE) Department of Economics, University of Oxford: Retrieved from: https://www.csae.ox.ac.uk/conferences/2008-EdiA/papers/290-Ataguba.pdf

Ataguba, J. T., Ichoku, H. E., \& Fonta, W. M. (2007). An estimation of the willingness to pay for community health care insurance scheme in rural Nigeria. A report presented during the $6^{\text {th }}$ Poverty and Economic Policy(PEP) Research Network General Meeting, Sheraton Lima Hotel, Paseo de la Republica 170, Lima, Peru. Retrieved from:

http://www.pep-net.org/fileadmin/medias/pdf/files_events/ataguba-pa.pdf

Autor, D. (2010). Compensated and Uncompensated Demand Function with an Application of Giffen Goods. [Lecture note6pdf] 40.13/14.003 Applied Microeconomics and Public Policy, Fall 2010. Retrieved from:

http://dspace.mit.edu/bitstream/handle/1721.1/109484/14-03-fall-2010/contents/lecture-notes/ MIT14_03F10_lec06.pdf

Binam, J. N., Ibrahim, D., \& Nkelzok, V. (2007). Community pre-payment of health care and estimation of the willingness to pay in Cameroon: evidence of rural households in the centre region: Contributed Paper prepared for presentation at the Twelfth African Econometric Society Conference, Southern Cap Sun, Cap town, South Africa. Retrieved from: http://africametrics.org/documents/conference07/Day\%203/Session\%208/nyemec $\quad$ k\%20 COMMUNITY\%20PRE-PAYMENT.pdf

Brown, J. D. (2000). What is Construct Validity? Statistic Corner. Questions and answers about language testing Statistics. Shiken: JACT Testing \& Evaluation SIG Newsletter, 4(2), 8-12. Retrieved from: http://hosted.jalt.org/test/bro_8.htm

Bukola, A., \& Usman, D. (2013). Willingness to Pay For Community Based Health Care Financing Scheme: A Comparative Study among Rural and Urban Households in Osun State, Nigeria; IOSR Journal of Dental and Medical Sciences, 5(6), 27-40, Retrieved from: http://www.iosrjournals.org/iosr-jdms/papers/Vol5-issue6/F0562740.pdf

Cameron, T. A. (1988). A New Paradigm for Valuing Non-market Goods Using Referendum Data: Maximum Likelihood Estimation by Censored Logistic Regression. Journal of Environmental Economics and Management, 15(3), 355-379.

https://doi.org/10.1016/0095-0696(88)90008-3 
Carrin, G., Waelkens, M. P., \& Criel, B. (2005). Community-based health insurance in developing countries: a study of its contribution to the performance of health financing systems. Tropical Medicine and International Health, 10, 799-811.

https://doi.org/10.1111/j.1365-3156.2005.01455.x

Champ, P. A., Bishop, R. C., Brown, T. C., \& McCollum, D. W. (1997). Using donation mechanisms to value nonuse benefits from public goods. Journal of Environmental Economic Management, 33(2), 151-162. https://doi.org/10.1006/jeem.1997.0988

Champ, P. A., Moore, R., \& Bishop, R. C. ( 2009). A Comparison of Approaches to Mitigate Hypothetical Bias. Agricultural and Resource Economics Review, 38(2), 166-180. https://doi.org/10.1017/S106828050000318X

Conroy, R. M. (2005). Stings in the tails: Detecting and dealing with censored data. The Stata Journal, 5(3), 395-404.

Defourny, J., \& Failon, J. (2008). Community-Based Health Insurance Schemes in Sub-Saharan Africa: Which Factors Really Influence Enrolment?: Working Paper Centre for Social Economy.

Dong, H., Kouyate, B., Cairns, J., \& Sauerborn, R. (2004). Differential willingness of household heads to pay community-based insurance premia for themselves and other household members. Health Policy and Planning, 19, 120-6.

https://doi.org/10.1093/heapol/czh014

Ejughemre, U. J. (2014). Scaling-up health insurance through Community based insurance, in rural Sub-Saharan African Communities. Journal of Hospital Administration, 3(1).

Haile, M., Ololo, S., \& Megersa, B. (2013). Willingness to join community-based health insurance among rural households of Debub Bench District, Bench Maji Zone, Southwest Ethiopia. BMC Public Health, 14, 59.

Hanemann, M., Loomis, W. J., \& Kanninen, B. (1991). Statistical efficiency of double-bounded dichotomous choice contingent valuation. American Journal of Agricultural Economics, 73, 1255-1263. https://doi.org/10.2307/1242453

Hoyos, D., \& Mariel, P. (2010). Contingent Valuation: Past, Present and Future. Prague Economic Papers, 4. https://doi.org/10.18267/j.pep.380

Kedir, A. (2011). Contigent Valuation Technique: A Review of Literature; ISABB Journal of Health and Environmental Science, 1(1), 8-16.

Loomis, J. B. (2013). Strategies for Overcoming Hypothetical Bias in Stated Preference Surveys. Journal of Agricaltural and Resource Economics 39(1), 34-46. Retrieved from: http://www.waeaonline.org/UserFiles/file/JAREApr20143Loomispp34-46.pdf

Noubiap, J. J., Joko, W. Y., Obama, J. M., Bigna, J. J., Bigna, J. J., \& Nzima, V. N. (2013). Community-based health insurance knowledge, concern, preferences, and financial planning for health care among informal sector workers in a health district of Douala, Cameroon; The 
Pan African Medical Journal, 16, 17. https://doi.org/10.11604/pamj.2013.16.17.2279

Oriakhi, H. O., \& Onemolease, E. A. (2012). Determinants of Rural Household's Willingness to Participate in Community Based Health Insurance Scheme in Edo State, Nigeria. Ethno Med, 6(2), 95-102.

Onwujekwe, O., Okereke, E., Onoka, C., Uzochukwu, B., Kirigia, J., \& Petu, A. (2009). Willingness to Pay for CBHI in Nigeria: do economics Status and place of residence matter? Health Policy and Planning, 25, 155-161. https://doi.org/10.1093/heapol/czp046

Singh, K. (2007). Quantitative social Research Method. Sage Publications, London. https://doi.org/10.4135/9789351507741

Thomas, A. (2007). Econometrics. Thomas Andren \& Ventus Publishing APS ISBN 978-877681-235-5: Retrieved from:

file://C:/Users/eshetu/Downloads/Econometrics\%20-\%20Andren\%20(1).pdf

Torres, O. (2007). Linear Regression using stata (V.6.3). Data and Statistical Service.

Retrieved from: http://dss.princetonedu/training

Tundui, C., \& Macha, R. (2014). Social Capital and Willingness to Pay for Community Based Health Insurance: Empirical Evidence from Rural Tanzania; Journal of Finance and Economics, 2(4), 50-67. https://doi.org/10.12735/jfe.v2i4p50

Weil, D. N. (2013). Health and Economic Growth. Prepared for the Handbook of Economic Growth, 2, 24, Retrievedfrom:

http://www.brown.edu/Departments/Economics/Faculty/David_Weil/Health_and_Economics _Growth_handbook_Article.pdf

WHO, (2005). Achieving universal health coverage: Developing the health financing system. Technical briefs for policy-makers No. 1. Geneva. Retrieved from:

http://www.who.int/health_financing/documents/pb_e_05_1-universal_cov.pdf

Wiesmann, D. (2000). The Emerging Movement of Community Based Health Insurance in Sub-Saharan Africa: Experiences and Lessons Learned. Retrieved from: http://www.oecd.org/dev/2510509.pdf

Williams, R. (2015). Interval Regression.University of Notre Dame.From stata 11 manual, 712: Retrieved from: https://www3.nd.edu/ rwilliam/stats3/intreg2.pdf

Wooldridge, J. M. (2002). Econometric Analysis of Cross Section and Panel Data. The MIT Press Cambridge Massachusetts London, England. Retrieved From:

https://www.academia.edu/4783248/Wooldridge_2002_econometric_analysis_of_cross_secti on_and_panel_data

Xu, K., Jeong, H., Saksena, P., Shin, J., Mathauer, I., \& Evans, D. (2010). Financial risk protection of National Health Insurance in the Republic of Korea: 1995-2007. World Health Report Background Paper, No 23: Retrieved from:

http://www.portal.pmnch.org/healthsystems/topics/financing/healthreport/23RepKorXU.pdf 


\section{Appendix 1.Socio- Demographic data, Prediction, goodness of fit and mean estimation}

1 Household Heads' Socio- Demographic Attributes

\begin{tabular}{|c|c|c|}
\hline Attributes & Frequency $(n=392)$ & Percentage (\%) \\
\hline \multicolumn{3}{|l|}{ Gender of the household head: } \\
\hline Male & 293 & 74.7 \\
\hline Female & 99 & 25.3 \\
\hline \multicolumn{3}{|l|}{ Age Group(in year): } \\
\hline $18-30$ & 39 & 10 \\
\hline $31-40$ & 108 & 27.5 \\
\hline $41-50$ & 152 & 38.8 \\
\hline $51-60$ & 76 & 19.4 \\
\hline$>=61$ & 17 & 4.3 \\
\hline \multicolumn{3}{|l|}{ Marital Status: } \\
\hline Married & 342 & 87.2 \\
\hline Single & 22 & 5.6 \\
\hline Unmarried & 28 & 7.1 \\
\hline \multicolumn{3}{|l|}{ Educational Status: } \\
\hline illiterate & 122 & 31 \\
\hline primary(1-6) & 209 & 53 \\
\hline secondary(7-12) & 61 & 16 \\
\hline \multicolumn{3}{|l|}{ Family Size Category: } \\
\hline$<=2$ & 37 & 9.4 \\
\hline $3-5$ & 131 & 33.4 \\
\hline $6-8$ & 181 & 46.2 \\
\hline$>=9$ & 43 & 11 \\
\hline \multicolumn{3}{|l|}{ Religion: } \\
\hline Orthodox & 226 & 57.6 \\
\hline Muslim & 148 & 37.8 \\
\hline Others & 18 & 4.6 \\
\hline \multicolumn{3}{|l|}{ Main Occupation: } \\
\hline Farming & 377 & 96 \\
\hline Petty trading & 15 & 4 \\
\hline Annual Income group (ETB): & 69 & 17.6 \\
\hline$<=20000$ & 170 & 43.4 \\
\hline $20001-40000$ & 142 & 36.2 \\
\hline $\begin{array}{l}40001-60000 \\
>60000\end{array}$ & 11 & 2.8 \\
\hline
\end{tabular}

Source: Computed from field survey, 2016

2. Marginal effects (prediction)

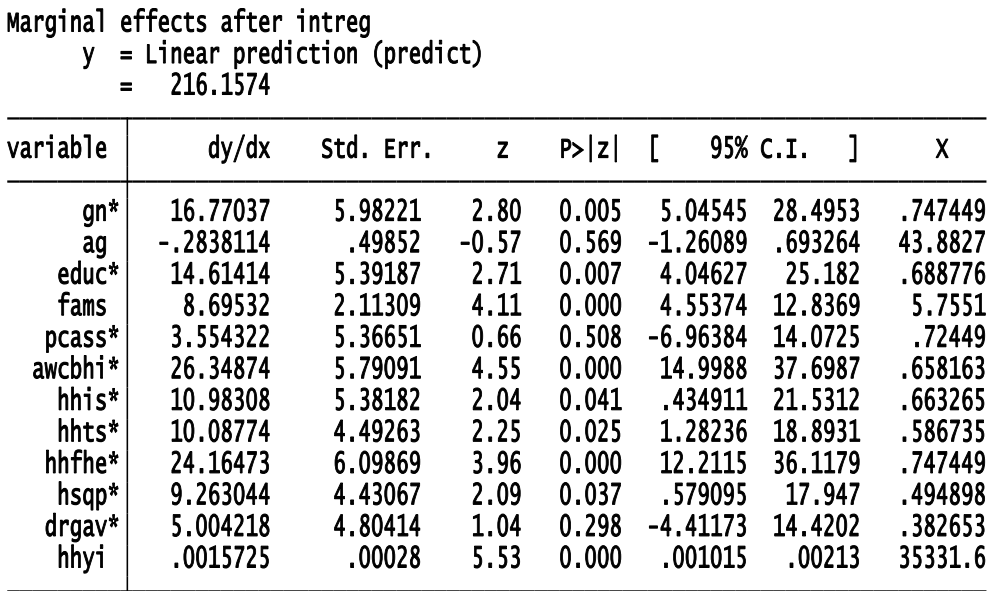

$\left.{ }^{*}\right) d y / d x$ is for discrete change of dummy variable from 0 to 1 
3. The model goodness of fit $\left(\mathrm{R}^{2}\right)$

- fitstat

Measures of Fit for intreg of lwtpc hwtpc

$\begin{array}{lrl}\text { Log-Lik Intercept on1y: } & -319.692 & \text { Log-Lik Fu11 Mode1: } \\ \text { D(378): } & 153.914 & \text { LR(12): } \\ & 0.759 & \text { Prob LCFadden's Adj R2: } \\ \text { MCFadden's R2: } & 0.710 & \text { Cragg \& Uh7er's R2: } \\ \text { Maximum Likelihood R2: } & 0.893 & \\ \text { MCKelvey and Zavoina's R2: } & 3568.455 & \text { Variance of error: } \\ \text { Variance of } y^{*}: & 0.464 & \text { AIC*n: } \\ \text { AIC: } & -2103.223 & \text { BIC': }\end{array}$

$-76.957$

485.470

0.000

0.715

0.883

381.244

181.914

$-413.814$

4 Estimate mean WTP (intreg lwtpc hwtpc)

Interval regression

Log likelihood $=-319.69154$ $\begin{array}{llr}\text { Number of obs } & = & 392 \\ \text { LR chi2(0) } & = & -0.00 \\ \text { Prob }>\text { chi2 } & = & \end{array}$

\begin{tabular}{r|rrcrrr}
\hline & Coef. & Std. Err. & $\mathrm{z}$ & $\mathrm{P}>|\mathrm{z}|$ & \multicolumn{2}{c}{ [95\% conf. Interval] } \\
\hline _cons & 211.1384 & 4.065251 & 51.94 & 0.000 & 203.1706 & 219.1061 \\
\hline /1nsigma & 4.189742 & .0493511 & 84.90 & 0.000 & 4.093015 & 4.286468 \\
\hline sigma & 66.00573 & 3.257454 & & & 59.92029 & 72.7092
\end{tabular}

5. Calibration Scales and WTP Intervals

From the scales, please indicate how much you are certain to pay the amount you agreed (yes response)

\begin{tabular}{|c|c|c|c|c|c|c|c|}
\hline $\begin{array}{l}\text { Very } \\
\text { uncertain (1) }\end{array}$ & $\begin{array}{l}\text { Uncertain } \\
\text { (2) }\end{array}$ & \multicolumn{2}{|c|}{$\begin{array}{l}\text { Probably } \\
\text { uncertain (3) }\end{array}$} & $\begin{array}{l}\text { I can say } \\
\text { nothing (4) }\end{array}$ & $\begin{array}{l}\text { Probably } \\
\text { certain (5) }\end{array}$ & \multirow{2}{*}{$\frac{\begin{array}{l}\text { Certai } \\
\text { n (6) }\end{array}}{\text { Outcome }}$} & \multirow{2}{*}{$\begin{array}{c}\text { Very certain } \\
\text { (7) } \\
\text { WTP interval } \\
\text { (Bli,Bhi) }\end{array}$} \\
\hline $\begin{array}{l}\text { Response to } \\
\text { first bid(Bfi) }\end{array}$ & $\begin{array}{l}\text { Response } t \\
\operatorname{bid}(\mathrm{B} 2 \mathrm{li} \text { or } \mathrm{B}\end{array}$ & $\begin{array}{l}\text { second } \\
2 \mathrm{hi})\end{array}$ & $\begin{array}{l}\text { Cer } \\
\text { to } \mathrm{f}\end{array}$ & $\begin{array}{l}\text { inty level } \\
\text { st bid }\end{array}$ & $\begin{array}{l}\text { Certainty level } \\
\text { to second bid }\end{array}$ & & \\
\hline \multirow[t]{2}{*}{ yes } & \multirow{2}{*}{\multicolumn{2}{|c|}{ yes }} & & - & $>=5$ & Yes-yes & $(\mathrm{B} 2 \mathrm{hi},+\infty)$ \\
\hline & & & & - & $<5$ & Yes-no & (Bfi,B2hi) \\
\hline \multirow[t]{2}{*}{ yes } & \multirow{2}{*}{\multicolumn{2}{|c|}{ no }} & & $>=5$ & - & Yes-no & (Bfi,B2hi) \\
\hline & & & & $<5$ & - & no-no & $(-\infty$, Bfi $)$ \\
\hline \multirow[t]{2}{*}{ no } & \multirow{2}{*}{\multicolumn{2}{|c|}{ yes }} & & - & $>=5$ & no-yes & (B2li,Bfi) \\
\hline & & & & - & $<5$ & no-no & $(-\infty, B 21 i)$ \\
\hline no & \multicolumn{2}{|c|}{ no } & & - & - & no-no & $(-\infty, B 21 i)$ \\
\hline
\end{tabular}

Note: for yes- yes responses, only the second higher bid response is calibrated because it seems logical that these respondents at least they could certainly pay the first bid.

\section{Copyright Disclaimer}

Copyright for this article is retained by the author(s), with first publication rights granted to the journal.

This is an open-access article distributed under the terms and conditions of the Creative Commons Attribution license (http://creativecommons.org/licenses/by/3.0/). 